\title{
Kidney Disease Cohort (KidDiCo) of Southern Denmark: Design, Coverage, Generalizability and Implications for Use
}

Jan Dominik Kampmann ${ }^{1,2}$ James Goya Heaf ${ }^{3}$

Christian Backer Mogensen ${ }^{2,4}$ Hans Mickley ${ }^{5}$

Frans Brandt ${ }^{1,2}$

'Department of Internal Medicine, Hospital of Southern Jutland, Sonderborg, 6400, Denmark; '2Department of Regional Health Research, University of Southern Denmark, Odense, 5230, Denmark; ${ }^{3}$ Department of Medicine, Zealand University Hospital, Roskilde, 4000, Denmark; ${ }^{4}$ Department of Emergency Medicine, Hospital of Southern Jutland, Aabenraa, 6200, Denmark; ${ }^{5}$ Department of Cardiology, Odense University Hospital, Odense, 5000, Denmark
Correspondence: Jan Dominik Kampmann Department of Internal Medicine, Hospital of Southern Jutland, Sydvang I, Sonderborg, 6400, Denmark

Tel +45 50340758

Email jdk@rsyd.dk
Background: This article provides a description of a large register of a population from the Region of Southern Denmark, the Kidney Disease Cohort (KiDiCo). Coverage and representativeness according to gender and education level are discussed.

Methods: Data for KiDiCo were obtained using laboratory databases from participating laboratories in the Region of Southern Denmark and were linked to individual personal 10digit personal identification numbers. The study population includes individuals over 18 years of age living in Denmark, whose serum creatinine was analysed in one of the 27 participating laboratories in the Region of Southern Denmark during the period of 8 years from 1st January 2006 to 31st December 2013. Individually linked data consist of diagnosis codes, date and cause of death, dispensed medicine data, socioeconomic data and demographic data. Results: In total, $\mathrm{n}=669,929$ individuals had their blood tested for creatinine between 2007 and 2013 in a defined geographical area. The estimated geographical coverage was $78 \%$. The median age of the background population was 6 years lower. The cohort had a slightly higher percentage of females (53\%) compared to the background population (49\%). Differences in educational levels reflect the minor age gap.

Conclusion: Based on coverage of $78 \%$ together with similar characteristics in terms of gender and age, the KiDiCo is a representative cohort of patients in the Region of Southern Denmark. Combining laboratory data with high-quality Danish administrative registers makes diverse research feasible.

Keywords: chronic kidney disease, acute kidney injury, epidemiology

\section{Introduction}

Chronic kidney disease (CKD) is a public health burden causing clinical and economic challenges. ${ }^{1,2}$ Ten percent of the world's population suffers from Kidney disease. ${ }^{3}$ CKD is an independent risk factor for the development of cardiovascular disease (CVD). ${ }^{4}$ Despite the increased risk of cardiovascular disease, the CKD population is largely ignored in large cardiovascular trials. More than $80 \%$ of trials excluded subjects with end-stage renal disease and $75 \%$ excluded patients with CKD. ${ }^{5}$

One of the biggest challenges in nephrology, is that large proportions of individuals with CKD remain undiagnosed. ${ }^{6}$ An American study $(\mathrm{n}=28,244)$ showed that only $9 \%$ of patients with CKD were aware of having renal impairment. ${ }^{7}$ Furthermore, screening programs for CKD are insufficient, or do not exist in many countries. ${ }^{8,9}$ 


\section{Graphical Abstract}

\section{Kidney Disease Cohort (KidDiCo) of Southern Denmark; design, coverage, generalizability and implications for use}
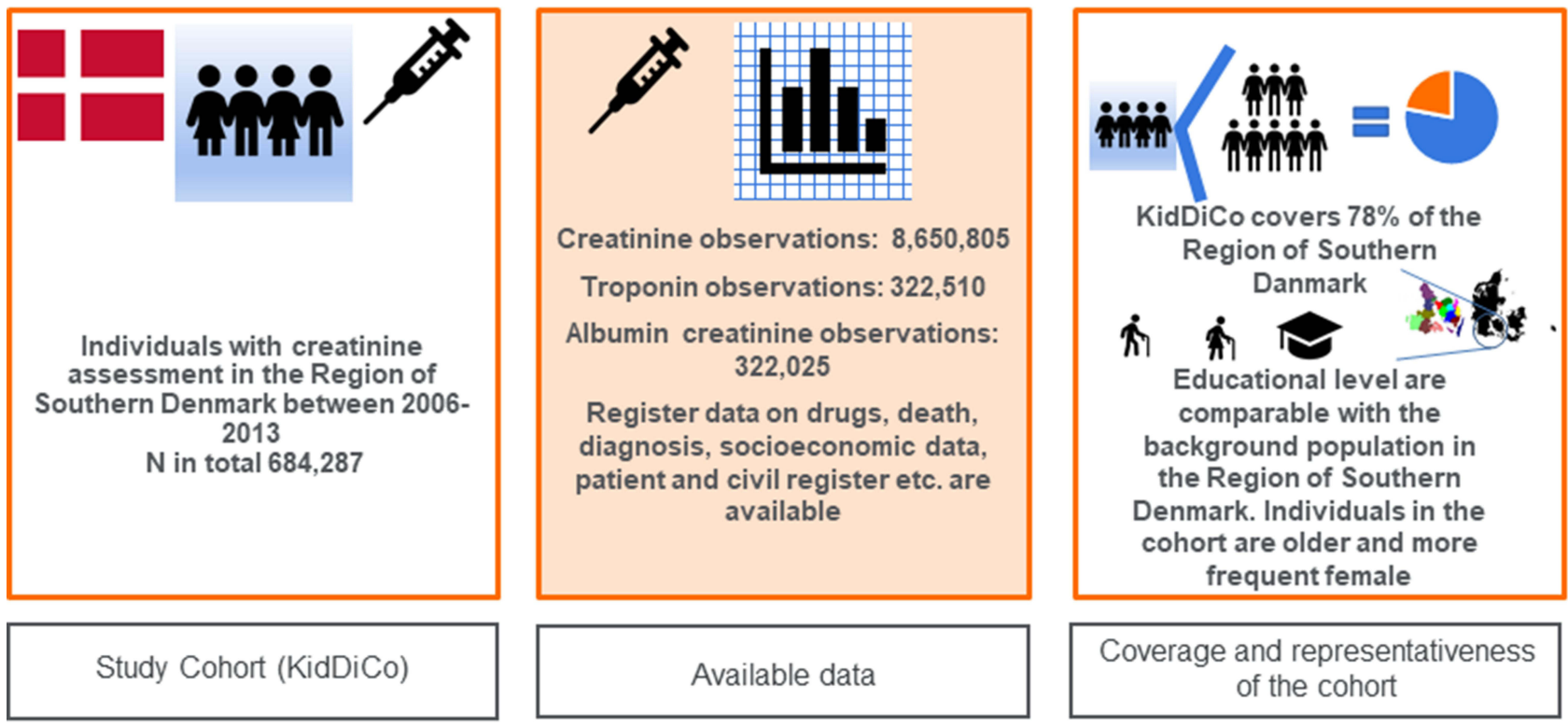

Coverage and representativeness of the cohort

Reported outcomes following acute kidney injury (AKI) are consistently poor, and there is an increasing body of evidence that AKI increases the risk of CKD. ${ }^{10,11}$

Early identification of individuals with CKD and AKI, followed by the implementation of evidence-based interventions, can slow down, or prevent the progression to advanced stages of the disease and reduce the risk of cardiovascular disease. $^{12}$

AKI and CKD International Classification of Diseases (ICD) codes have been found unreliable in register studies underlining the need for creatinine-based cohorts when investigating renal disease. ${ }^{13,14}$

The aim of this study is to establish the representativeness and coverage of our cohort. Assessment of the general quality of the cohort could emphasize the validity of future research with the study data.

\section{Materials and Methods}

\section{Ethics}

The study was approved by the Danish Data Protection Agency (19/20983), and the regional legal board (20/
40602). Furthermore, the study was reported to the Regional Committee on Health Research Ethics for Southern Denmark (20192000-69). However, ethical approval for this register study was not deemed necessary.

\section{Laboratory Values}

Data from all but one laboratory in the Region of Southern Denmark were available, as the method involved in accessing data from the laboratory in question could not be aligned with the other participating laboratories. Laboratory values included serum samples of creatinine and troponin and urine samples of albumin/creatinine ratio from patients aged 18 or above. Laboratory data were provided by the central laboratories in Kolding and Odense, respectively, covering data on the island of Funen and South Jutland.

An overall number of 9,296,617 blood and urine samples were requisitioned, mostly by hospital in- and outpatients (55\%) and general practitioners (41\%) (Figure 1). All the above-mentioned blood and urine samples analyzed in any of the participating laboratories were considered raw data. 


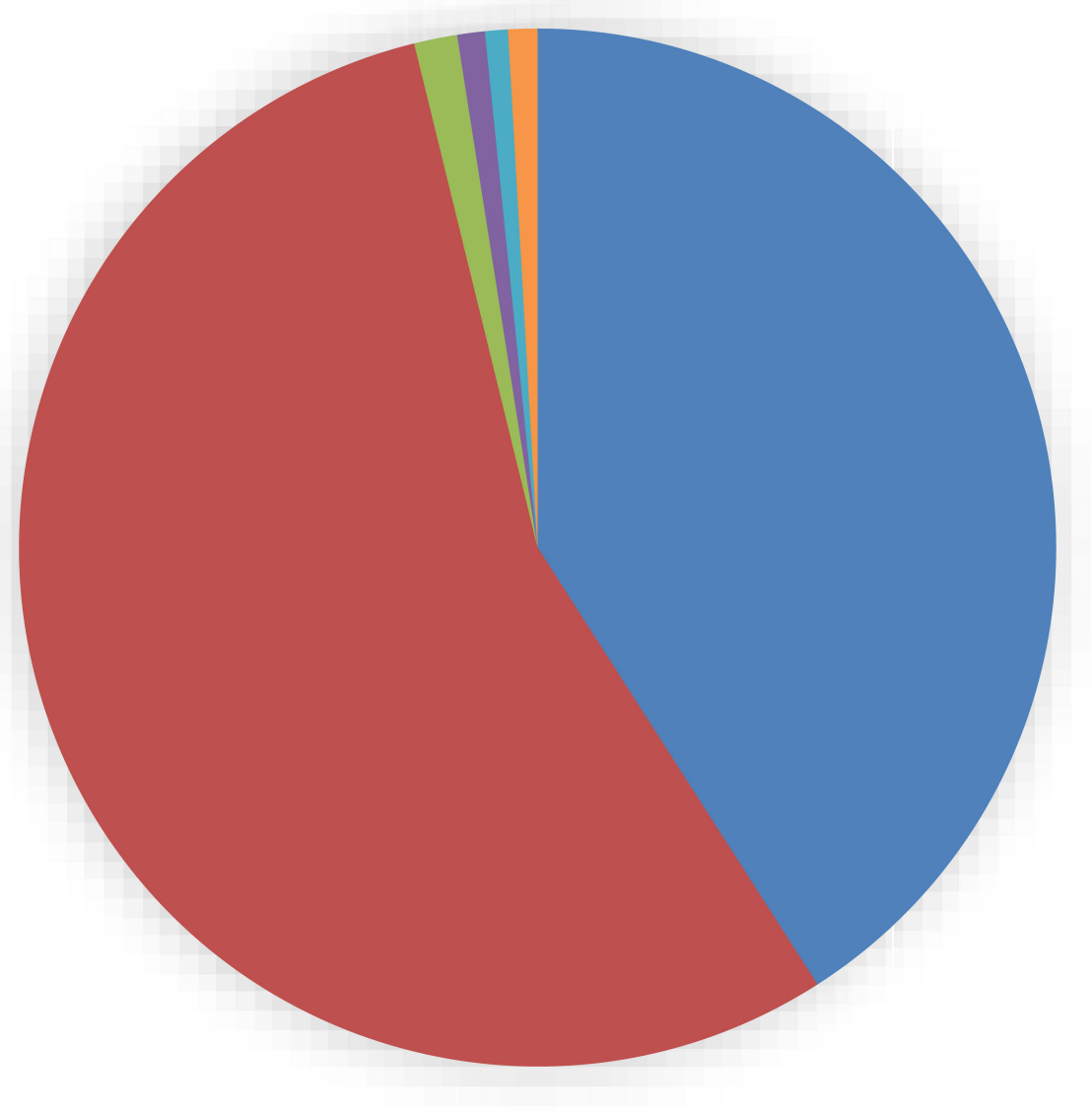

- General Practitioner 41\%

Hospital 55\%

- Specialist $1 \%$

Psychiatric hospitals 1\%

Private hospitals $1 \%$

others $1 \%$

Figure I Contribution of requests of all blood and urine samples as raw data collected for the Kidney Disease Cohort (KidDiCo).

Creatinine was measured via Jaffe and enzymatic assay. The Jaffe method is in excellent agreement with the enzymatic assay, leading to minimal differences only in the reference range. ${ }^{15}$ All Danish citizens are assigned a unique ten-digit personal identification number at birth through the Danish Civil Registration System (DCRS). ${ }^{16}$ The DCRS provides the possibility of linking samples to personal identification numbers and gaining access to demographic data, providing rich and thorough information on individuals in the cohort.

In order to estimate the glomerular filtration rate (eGFR), the Chronic Kidney Disease Epidemiology Collaboration (CKD-EPI) formula was used. The formula has been proven valid and is recommended by the Kidney Disease: Improving Global Outcomes (KDIGO) guidelines. ${ }^{17}$

\section{Study Population}

In 2013, the Region of Southern Denmark included $\mathrm{n}=1,201,419$ inhabitants accounting for $21 \%$ of the entire population of Denmark. ${ }^{18}$ Southern Denmark has been shown to be representative of most socioeconomic and healthcare aspects, when compared to the entire Danish population. ${ }^{18}$

The cohort included individuals over 18 years of age in possession of a national identity number, who had at least one blood sample analyzed for creatinine by one of the participating laboratories in the Region of Southern Denmark from 1st of January 2006 until 31st of December 2013 (Figure 2). These patients represent the entire Kidney Disease Cohort (KidDiCo). A further specification was performed in terms of residency.

In order to define the geographical area of our cohort, only municipalities associated with the featured laboratories were considered as cohort catchment areas and was confirmed by the respective laboratories. The geographical area consists of 17 out of 22 municipalities in the Region of Southern Denmark (Figure 3). Due to a change in community coding, data from 2007 are only available to define the relevant municipalities definitively by the Danish Population Register. 

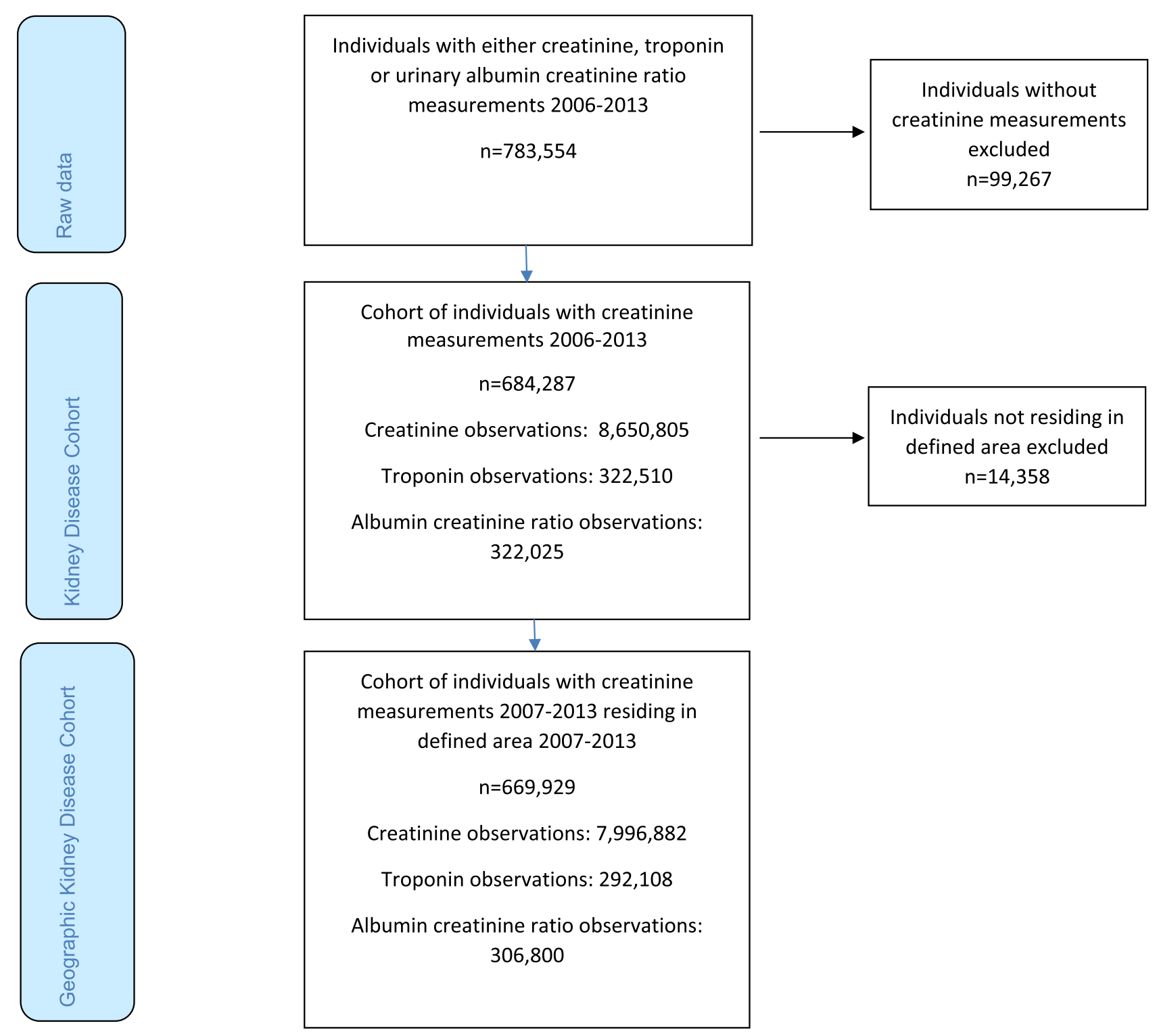

Figure 2 Flowchart on patients included in the Kidney Disease Cohort showing number of individuals in terms of; raw data, Kidney Disease Cohort and geographical Kidney Disease Cohort.

All individuals who were registered as resident in one of the 17 municipalities at any stage during 2007-2013, and had at least one creatinine analyzed in the participating laboratories during 2007-2013, were eligible for the geographic KidDiCo. Confirmation of residency was acquired by linking the individual patients with the Danish Population Database.

\section{Databases and Registries}

The laboratory data were linked with the population register, the Danish National Patient Register (DNPR), the Danish National Prescription Registry (DNPrR), DCRS, the Education Register, the Employment Classification Module Register, and the Danish Death Register.
Data on prescribed drugs can be retrieved from prescription databases, which contain records on the type of drug, the date of dispensation and the quantity of all prescribed drugs, dispensed from Danish pharmacies. ${ }^{19,20}$

Denmark offers government-funded universal healthcare and has a tradition of recordkeeping, which creates the possibility for individual-level linkage between registers. ${ }^{21}$ The DCRS contains information on demographics, vital status, date of death and residence of all persons living or having lived in Denmark. ${ }^{22}$ DCRS is continuously used for administrative purposes, is subject to ongoing validation, and registration is required by law. $^{23}$ 


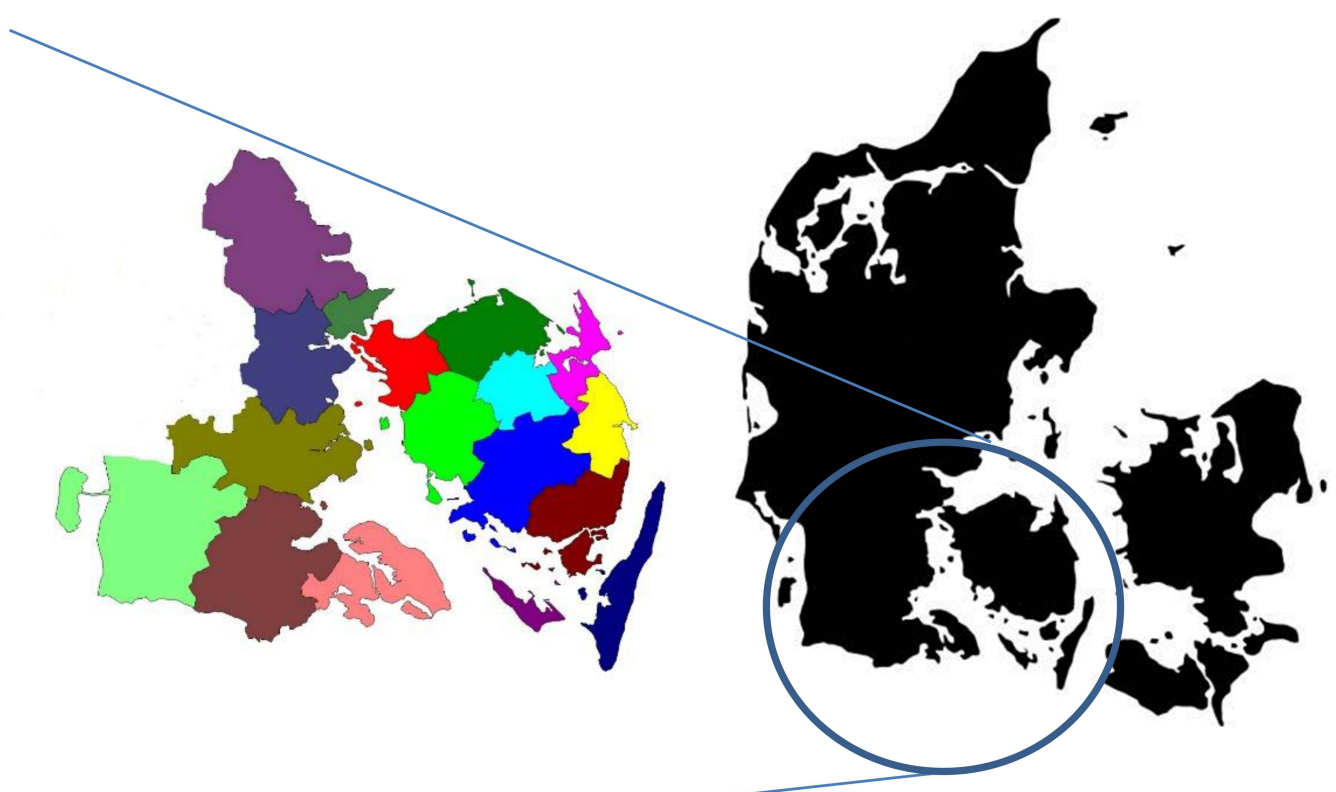

Figure 3 A geographical presentation of the municipalities in the Region of Southern Denmark in which contributing laboratories were situated. Maps of municipalities with courtesy from the Department of Regional Development, Global Goals and Analysis in the Region of Southern Denmark (edited by the author). Denmark map GettylmagesI I 44785834 (edited by the author). Permission to use geographical material in this study has been granted.

DNPR has contained data on all contacts to Danish hospitals since 1977. From 1995 outpatient diagnosis and emergency department contacts have been included in the register. ${ }^{24}$ The registration of diagnoses is based on the Danish edition of the International Classification of Diseases, using the 10th revision (ICD-10) from 1994 and until now. It is generally accepted that the information recorded is of a very high quality. ${ }^{23}$

The DNPrR was established in 1994 and contains information on all drugs sold in Danish community pharmacies, according to the Anatomical Therapeutic Chemical (ATC)code $^{22}$ Due to reimbursement driven record keeping, the DNPrR provides data of a high quality. Previous studies in the Region of Southern Denmark found an overall coverage as high as $83 \%$ for redeemed prescriptions. ${ }^{14}$

The Danish Register of Causes of Death records all deaths of Danish citizens since 1875. From 1994 and onward ICD-10 codes have been used to classify the causes of death. Mandatory completion of a death certificate makes the registry valid. ${ }^{25}$

An overview of the accessible registries and databases is shown in Figure 4 and Table 1.

\section{Coverage}

Coverage was estimated by comparing the number of individuals, who resided at one stage in one of the 17 municipalities between 2007 and 2013, who had at least one creatinine measured during 2007-2013 in the associated laboratories (geographical KidDiCo); with the entire population with all individuals aged 18 years and above, who lived in the 17 municipalities during 2007 and 2013. Data on the background population were obtained from Denmark Statistics (DST). The method of estimating the coverage is in concordance with previous studies. ${ }^{14,26}$

\section{Representativeness}

Representativeness was established in relation to age, gender and educational level using the geographical KidDiCo. Data for the background population were obtained from DST. Age and educational level in the cohort were defined at measurement of the first available creatinine. Age is presented as the median age in Table 2 .

The educational levels were divided into short, middle, long and missing data. Short education levels include primary school, high school and further adult education. Medium education level includes bachelor's degree or further education at bachelor level. Long education levels refer to masters and doctorates. Missing information was stated as missing in the table if no data was available from the database, or if the data on highest level of education was obtained after the first available creatinine was measured. 


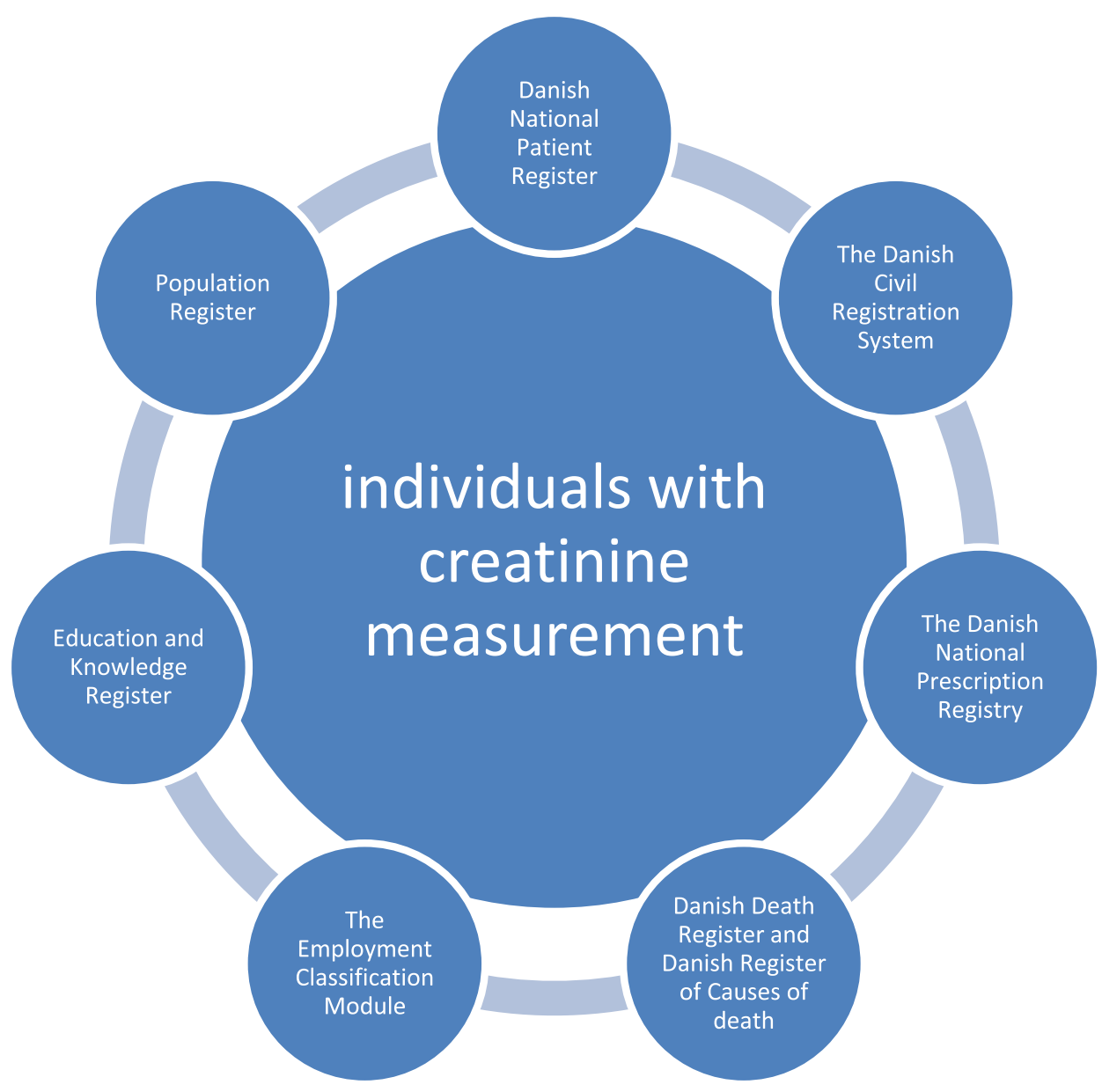

Figure $4 \mathrm{~A}$ presentation of the Kidney Disease Cohort and registers linked via personal identification number.

The time point for age and educational level assessment of the background population was defined as the first time the resident was registered in one of the 17 municipalities, while 18 years of age or older. The STROBE cohort checklist was employed when writing the report. ${ }^{27}$

\section{Assessment of Renal Function}

To estimate the glomerular filtration rate (GFR), the Chronic Kidney Disease Epidemiology Collaboration (CKD-EPI) formula was used, which is recommended by "Kidney Disease: Improving Global Outcomes" (KDIGO) guidelines (5). In case of multiple creatinine measurements during the same day, the highest creatinine value was used to estimate GFR. Creatinine was measured either enzymatically or with the Jaffe method.

Advanced CKD was defined by one eGFR under $60 \mathrm{~mL} / \mathrm{min} / 1.73 \mathrm{~m}^{2}$ and another estimated GFR under $60 \mathrm{~mL} / \mathrm{min} / 1.73 \mathrm{~m}^{2}$ at, at least three months, however, no longer than 12 months apart. No eGFR levels may be above $60 \mathrm{~mL} / \mathrm{min} / 1.73 \mathrm{~m}^{2}$ between the two above measurements, as recommended by KDIGO guidelines (5).

Renal transplant patients and patients on dialysis were defined as ESRD patients regardless of their eGFR. In order to identify dialysis patients in The Danish National Patient Register (DNPR), the ICD-10 codes Z99.2 and Z94.0 were used.

\section{Results}

The KidDiCo features 27 laboratories in 22 municipalities and thus, covers the majority of the Region of Southern Denmark. Between 2006 and 2013 creatinine was measured in $\mathrm{n}=684,287$ individuals. This provided $8,650,805$ creatinine measurements, 322,510 troponin observations and 322,025 albumin creatinine ratio observations (Figure 2). When correcting for patients who lived in a defined area at one stage between 2007 and 2013, the number of individuals falls slightly to $n=669,929$ (Figure 2). During the same time period, $n=857,854$ patients above the age of 18 lived in the 
Table I Contents and Time Range of Registers Linked with the Kidney Disease Cohort

\begin{tabular}{|c|c|c|}
\hline Register & Contents & Time Range \\
\hline $\begin{array}{l}\text { The Danish Civil } \\
\text { Registration System }\end{array}$ & $\begin{array}{l}\text { Age } \\
\text { Sex }\end{array}$ & 1968-present \\
\hline National Patient Register & $\begin{array}{l}\text { Diagnosis } \\
\text { Department } \\
\text { Type of referral } \\
\text { Type of admission } \\
\text { Hospital } \\
\text { Admission and } \\
\text { discharge date } \\
\text { Admission time }\end{array}$ & $1977-2018$ \\
\hline $\begin{array}{l}\text { Danish national } \\
\text { prescription register }\end{array}$ & $\begin{array}{l}\text { Brand name } \\
\text { ATC-Code* } \\
\text { ABC-Code } \\
\text { Amount } \\
\text { Dosage } \\
\text { Pack size } \\
\text { Strength } \\
\text { Indication } \\
\text { Date of dispensing } \\
\text { Issuer of prescription } \\
\text { Price }\end{array}$ & 2006-2019 \\
\hline Population register & Residency & $197 \mid-2019$ \\
\hline $\begin{array}{l}\text { Education and Knowledge } \\
\text { register }\end{array}$ & Educational level & $1977-2020$ \\
\hline $\begin{array}{l}\text { The Employment } \\
\text { Classification Module }\end{array}$ & $\begin{array}{l}\text { Occupational and } \\
\text { income status }\end{array}$ & $2006-2018$ \\
\hline Danish death register & Date of death & $1978-2019$ \\
\hline Laboratory values & $\begin{array}{l}\text { Creatinine } \\
\text { Troponin } \\
\text { Albumin Creatinine } \\
\text { Ratio }\end{array}$ & $2006-2013$ \\
\hline $\begin{array}{l}\text { Danish Register of causes } \\
\text { of death }\end{array}$ & Causes of death & $1978-2019$ \\
\hline
\end{tabular}

Notes: *ATC-code, Therapeutical Chemical Classification System.

defined KidDiCo area, resulting in a coverage of $78 \%$ (Table 2). The gender distribution in the background population was distributed evenly with $\mathrm{n}=432,959$ (50.5\%) male and $n=424,895$ (49.5\%) females (Table 2). In the KidDiCo, a slight overweight of females $\mathrm{n}=360,172(53.8 \%)$ was found in comparison to males $\mathrm{n}=309,757$ (46.2\%) (Table 2). The median age was 6.4 years higher in the KidDiCo, when compared with the background population. When stratifying the background population by age, $24 \%$
Table 2 Coverage and Representativeness of the Kidney Disease Cohort

\begin{tabular}{|c|c|c|}
\hline & $\begin{array}{l}\text { General Population } \\
\text { in the } \\
\text { Geographically } \\
\text { Defined Area } \\
2007-2013\end{array}$ & $\begin{array}{l}\text { Kidney Disease } \\
\text { Cohort Corrected } \\
\text { for Geographical } \\
\text { Area 2007-2013 }\end{array}$ \\
\hline$N$ in total & 857,854 & 669,929 \\
\hline \multicolumn{3}{|l|}{ Gender } \\
\hline Male & 432,959 (50.47\%) & 309,757 (46.24\%) \\
\hline Female & 424,895 (49.53\%) & 360,172 (53.76\%) \\
\hline Age median & 45.0 & 51.4 \\
\hline \multicolumn{3}{|l|}{$\begin{array}{l}\text { Educational } \\
\text { level }\end{array}$} \\
\hline Short & 660,034 (77\%) & $487,399(73 \%)$ \\
\hline Medium & II2,806 (I3\%) & 139,629 (21\%) \\
\hline Long & 36,225 (4\%) & $12,790(2 \%)$ \\
\hline Missing & $48,789(6 \%)$ & 30,111 (4\%) \\
\hline
\end{tabular}

were between 18 and 30 years of age, compared to $15 \%$ in the KidDiCo (Table 2). Among the total population of 60 89 year olds, the proportion was $4 \%$ higher among 70 79 year olds and 5\% higher among 60-69 year olds in the KidDiCo group, when compared to the background population (Figure 5). Data on the educational level show a higher proportion of medium educational level individuals in KidDiCo (21\%) compared to the background population (13\%) (Figure 5). The number of individuals with short and long education as the highest achieved education level, were very similar with $4 \%$ and $2 \%$ difference only, respectively (Table 2). The missing data were $6 \%$ in the background population compared to $4 \%$ in KidDiCo (Table 2).

When using the KDIGO guideline definition for CKD, a total of $n=66,486$ patients had CKD stage 3-5. The crude prevalence was $9.93 \%$ accordingly.

Patients with ESRD, defined as patients on dialysis or with a kidney transplant, accounted for $n=566(0.85 \%)$ of the CKD population in the cohort.

\section{Discussion}

KidDiCo is a representative cohort with an excellent coverage for the Region of Southern Denmark. It contains data on gender, age, drugs, place of residence, date and cause of death and socio-economic status. All registers can be linked to individuals. The quality of Danish registers is 


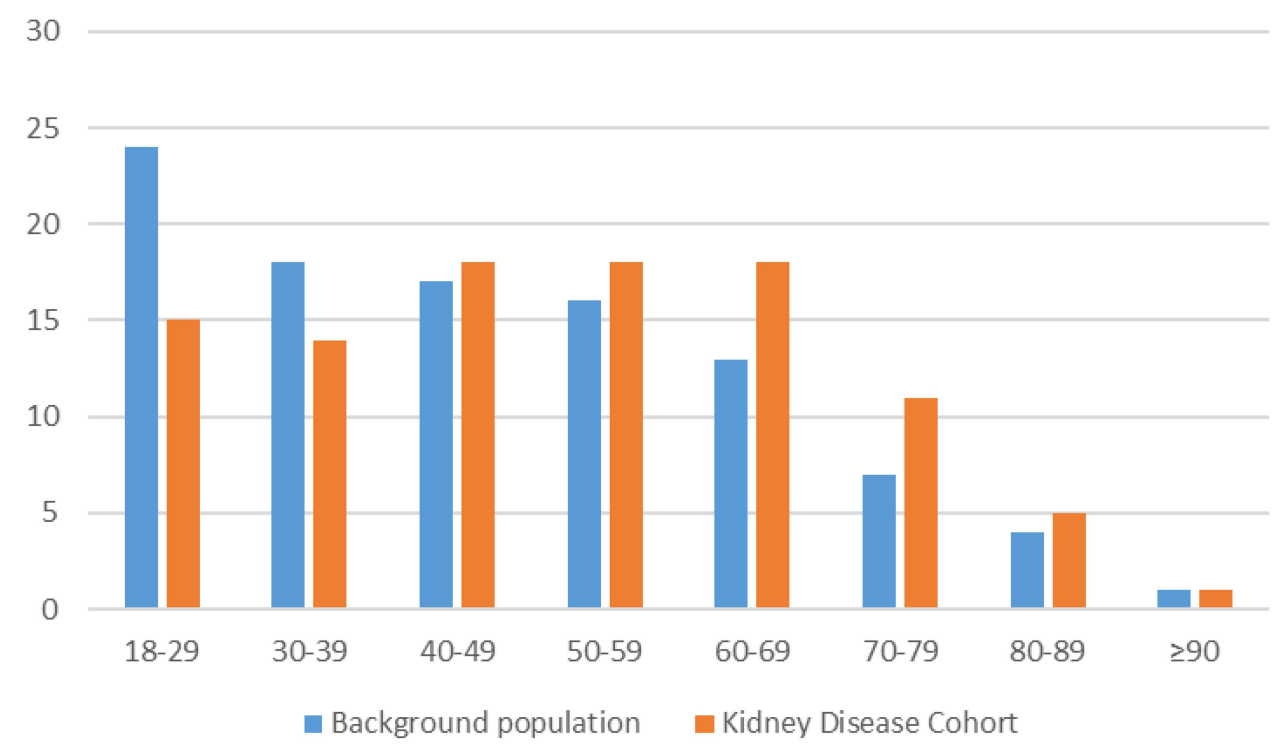

Figure 5 Age stratification divided into age group in years in the Kidney Disease Cohort and background population in the defined geographical area.

overall excellent. Based on the above, KidDiCo provides a useful database for future studies.

The coverage of $78 \%$ is high, compared to $66 \%$ in similar studies. ${ }^{14,26}$ A higher median age in KidDiCo of 45 years compared 43 years in a comparable register could offer one explanation. ${ }^{14}$ The cohort has a slightly higher percentage of women and the median age is slightly higher in comparison to the background population. This has also been the case in previous studies. ${ }^{14,28}$ The higher percentage of females might be explained by the fact that women tend to visit doctors more frequently and thereby, have creatinine measured more frequently. ${ }^{29}$ Pregnancy may have played a role as well. The higher median age might reflect the assumption that older individuals are more likely to visit doctors or be admitted to hospital. Likewise, the coverage of 18-29-year-old individuals is lower, and this should be taken into account when interpreting results from the cohort.

Our study has some limitations. A selection bias may exist, as only individuals whose creatinine was measured are part of the cohort. This may account for an overrepresentation of older and sicker individuals in the cohort. Important parameters, such as blood pressure measurements and body mass index data, are not included in the cohort. However, specific ATC and ICD codes can be used as surrogate markers.

With regard to missing data, individuals living in the cohort catchment area, might have blood and urine samples analyzed in another laboratory outside the catchment area. There was no minimum length of stay value to define residency, and individuals may have moved in and out of the catchment area during the inclusion time. However, our definition of residency has been used in the two previous cohort studies and is, therefore, considered valid. ${ }^{14,28}$ Furthermore, according to the Danish National Statistics, most individuals who move, move within their municipality and are aged 20-30 years old which corresponds to a small number in the cohort (https://www.dst. $\mathrm{dk} / \mathrm{da} /$ Statistik/emner/befolkning-og-valg/flytninger/flytnin ger-internt-i-danmark).

However, it should be mentioned that the coverage percentage is an approximation and may not be completely identical to the defined population.

We are interested in collaboration with other researchers. The cohort can be accessed by contacting the corresponding author. New projects would, of course, require approval by various Danish national bodies in order to guarantee research integrity. A list of examples for future research projects can be found as Supplementary Material.

\section{Conclusion}

Based on the coverage of $78 \%$ together with a close accordance in terms of gender and age, the KiDiCo is a representative cohort of patients in the Region of Southern Denmark. A combination of laboratory data with high-quality Danish administrative registers renders diverse research feasible. 


\section{Abbreviations}

KiDiCo, Kidney Disease Cohort; CKD, chronic kidney disease; CVD, cardiovascular disease; AKI, acute kidney injury; DCRS, Danish Civil Registration System; eGFR, estimated glomerular filtration rate; CKD-EPI, Chronic Kidney Disease Epidemiology Collaboration; KDIGO, Kidney Disease: Improving Global Outcomes; DNPR, Danish national patient register; DNPrR, The Danish National Prescription Registry; ICD-10, 10th revision of the International Classification of Diseases; ATC, Anatomical Therapeutic Chemical; DST, Denmark Statistics.

\section{Acknowledgments}

This work was supported by the University of Southern Denmark, the Region of Southern Denmark, Hospital of Southern Jutland and Knud and Edith Erichsen's Fund. We would like to thank Jan Hellden, Jens Hastrup, Donna Lykke Wolf and Eithne Hayes Bauer.

\section{Disclosure}

The authors report no conflicts of interest in this work.

\section{References}

1. Alebiosu CO, Ayodele OE. The global burden of chronic kidney disease and the way forward. Ethn Dis. 2005;15(3):418-423.

2. Go AS, Chertow GM, Fan D, McCulloch CE, Hsu CY. Chronic kidney disease and the risks of death, cardiovascular events, and hospitalization. $N$ Engl $J$ Med. 2004;351(13):1296-1305. doi:10.1056/NEJMoa041031

3. Bello AK, Levin A, Tonelli M, et al. Assessment of global kidney health care status. JAMA. 2017;317(18):1864. doi:10.1001/ jama.2017.4046

4. Cai Q, Mukku VK, Ahmad M. Coronary artery disease in patients with chronic kidney disease: a clinical update. Curr Cardiol Rev. 2013;9(4):331-339. doi:10.2174/1573403X10666140214122234

5. Charytan D, Kuntz RE. The exclusion of patients with chronic kidney disease from clinical trials in coronary artery disease. Kidney Int. 2006;70(11):2021-2030. doi:10.1038/sj.ki.5001934

6. Echouffo-Tcheugui JB, Kengne AP. Risk models to predict chronic kidney disease and its progression: a systematic review. PLoS Med. 2012;9(11):e1001344. doi:10.1371/journal.pmed.1001344

7. Whaley-Connell A, Shlipak MG, Inker LA, et al. Awareness of kidney disease and relationship to end-stage renal disease and mortality. Am J Med. 2012;125(7):661-669. doi:10.1016/j. amjmed.2011.11.026

8. Li C, Wen XJ, Pavkov ME, et al. Awareness of kidney disease among US adults: findings from the 2011 behavioral risk factor surveillance system. Am J Nephrol. 2014;39(4):306-313. doi:10.1159/000360184

9. Ravera M, Noberasco G, Weiss U, et al. CKD awareness and blood pressure control in the primary care hypertensive population. $A m$ J Kidney Dis. 2011;57(1):71-77. doi:10.1053/j.ajkd.2010.08.022

10. Chertow GM, Burdick E, Honour M, Bonventre JV, Bates DW. Acute kidney injury, mortality, length of stay, and costs in hospitalized patients. J Am Soc Nephrol. 2005;16(11):3365-3370. doi:10.1681/ ASN.2004090740
11. Stack AG, Casserly LF, Cronin CJ, et al. Prevalence and variation of chronic kidney disease in the Irish health system: initial findings from the national kidney disease surveillance programme. BMC Nephrol. 2014;15(1):185. doi:10.1186/1471-2369-15-185

12. Levey AS, Coresh J. Chronic kidney disease. Lancet. 2012;379 (9811):165-180. doi:10.1016/S0140-6736(11)60178-5

13. Sawhney S, Robinson HA, van der Veer SN, et al. Acute kidney injury in the UK: a replication cohort study of the variation across three regional populations. BMJ Open. 2018;8(6):e019435. doi:10.1136/bmjopen-2017-019435

14. Henriksen DP, Damkier P, Hallas J, Nybo M. Sixteen years of creatinine measurements among 460000 individuals-The Funen Laboratory Cohort (FLaC), a population-based pharmacoepidemiological resource to study drug-induced kidney disease. Basic Clin Pharmacol Toxicol. 2019;124(5):582-590. doi:10.1111/bcpt.13167

15. Junge W, Wilke B, Halabi A, Klein G. Determination of reference intervals for serum creatinine, creatinine excretion and creatinine clearance with an enzymatic and a modified Jaffe method. Clin Chim Acta. 2004;344(1-2):137-148. doi:10.1016/j.cccn.2004.02.007

16. Schmidt M, Pedersen L, Sorensen HT. The Danish civil registration system as a tool in epidemiology. Eur J Epidemiol. 2014;29 (8):541-549. doi:10.1007/s10654-014-9930-3

17. Kidney Disease: Improving Global Outcomes (KDIGO) CKD Work Group. KDIGO 2012 clinical practice guidelines for the evaluation and management of chronic kidney disease. Kidney Int Suppl. 2013;3:1-150.

18. Henriksen DP, Rasmussen L, Hansen MR, Hallas J, Pottegard A. Comparison of the five Danish regions regarding demographic characteristics, healthcare utilization, and medication use-a descriptive cross-sectional study. PLoS One. 2015;10(10):e0140197. doi:10.1371/journal.pone.0140197

19. Pottegard A, Schmidt SAJ, Wallach-Kildemoes H, Sorensen HT, Hallas J, Schmidt M. Data resource profile: the Danish national prescription registry. Int J Epidemiol. 2017;46(3):798-f.

20. Ehrenstein V, Antonsen S, Pedersen L. Existing data sources for clinical epidemiology: Aarhus University prescription database. Clin Epidemiol. 2010;2:273-279. doi:10.2147/CLEP.S13458

21. Frank L. Epidemiology. The epidemiologist's dream: Denmark. Science. 2003;301(5630):163. doi:10.1126/science.301.5630.163

22. Thygesen LC, Daasnes C, Thaulow I, Bronnum-Hansen H. Introduction to Danish (nationwide) registers on health and social issues: structure, access, legislation, and archiving. Scand J Public Health. 2011;39(7 Suppl):12-16. doi:10.1177/1403494811399956

23. Pedersen CB. The Danish civil registration system. Scand J Public Health. 2011;39(7 Suppl):22-25. doi:10.1177/1403494810387965

24. Schmidt M, Schmidt SA, Sandegaard JL, Ehrenstein V, Pedersen L, Sorensen HT. The Danish national patient registry: a review of content, data quality, and research potential. Clin Epidemiol. 2015;7:449-490. doi:10.2147/CLEP.S91125

25. Helweg-Larsen K. The Danish register of causes of death. Scand J Public Health. 2011;39(7 Suppl):26-29. doi:10.1177/1403494811399958

26. Runesson B, Gasparini A, Qureshi AR, et al. The Stockholm CREAtinine Measurements (SCREAM) project: protocol overview and regional representativeness. Clin Kidney J. 2016;9(1):119-127. doi:10.1093/ckj/sfv117

27. von Elm E, Altman DG, Egger M, et al. The strengthening the reporting of observational studies in epidemiology (STROBE) statement: guidelines for reporting observational studies. Epidemiology. 2007;18(6):800-804. doi:10.1097/EDE.0b013e3181577654

28. Runesson B, Qureshi AR, Xu H, et al. Causes of death across categories of estimated glomerular filtration rate: the Stockholm CREAtinine Measurements (SCREAM) project. PLoS One. 2019;14 (1):e0209440. doi:10.1371/journal.pone.0209440

29. Moller-Leimkuhler AM. Barriers to help-seeking by men: a review of sociocultural and clinical literature with particular reference to depression. J Affect Disord. 2002;71(1-3):1-9. doi:10.1016/S01650327(01)00379-2 


\section{Publish your work in this journal}

Clinical Epidemiology is an international, peer-reviewed, open access, online journal focusing on disease and drug epidemiology, identification of risk factors and screening procedures to develop optimal preventative initiatives and programs. Specific topics include: diagnosis, prognosis, treatment, screening, prevention, risk factor modification,

Submit your manuscript here: https://www.dovepress.com/clinical-epidemiology-journal systematic reviews, risk \& safety of medical interventions, epidemiology \& biostatistical methods, and evaluation of guidelines, translational medicine, health policies \& economic evaluations. The manuscript management system is completely online and includes a very quick and fair peer-review system, which is all easy to use. 